\title{
Understanding improved osteoblast behavior on select nanoporous anodic alumina
}

\author{
This article was published in the following Dove Press journal: \\ International Journal of Nanomedicine \\ 10 July 2014 \\ Number of times this article has been viewed
}

\author{
Siyu $\mathrm{Ni}^{\prime}$ \\ Changyan $\mathrm{Li}^{\prime}$ \\ Shirong $\mathrm{Ni}^{2}$ \\ Ting Chen' \\ Thomas J Webster ${ }^{3,4}$ \\ 'College of Chemistry, Chemical \\ Engineering and Biotechnology, \\ Donghua University, Shanghai, People's \\ Republic of China; ${ }^{2}$ Department of \\ Pathophysiology, Wenzhou Medical \\ University, Wenzhou, People's \\ Republic of China; ${ }^{3}$ Department of \\ Chemical Engineering, College of \\ Engineering, Northeastern University, \\ Boston, MA, USA; ${ }^{4}$ Center of \\ Excellence for Advanced Materials \\ Research, King Abdulaziz University, \\ Jeddah, Saudi Arabia
}

\begin{abstract}
The aim of this study was to prepare different sized porous anodic alumina (PAA) and examine preosteoblast (MC3T3-E1) attachment and proliferation on such nanoporous surfaces. In this study, PAA with tunable pore sizes $(25 \mathrm{~nm}, 50 \mathrm{~nm}$, and $75 \mathrm{~nm}$ ) were fabricated by a two-step anodizing procedure in oxalic acid. The surface morphology and elemental composition of PAA were characterized by field emission scanning electron microscopy and $\mathrm{X}$-ray photoelectron spectroscopy analysis. The nanopore arrays on all of the PAA samples were highly regular. X-ray photoelectron spectroscopy analysis suggested that the chemistry of PAA and flat aluminum surfaces were similar. However, contact angles were significantly greater on all of the PAA compared to flat aluminum substrates, which consequently altered protein adsorption profiles. The attachment and proliferation of preosteoblasts were determined for up to 7 days in culture using field emission scanning electron microscopy and a Cell Counting Kit-8. Results showed that nanoporous surfaces did not enhance initial preosteoblast attachment, whereas preosteoblast proliferation dramatically increased when the PAA pore size was either $50 \mathrm{~nm}$ or $75 \mathrm{~nm}$ compared to all other samples $(P<0.05)$. Thus, this study showed that one can alter surface energy of aluminum by modifying surface nano-roughness alone (and not changing chemistry) through an anodization process to improve osteoblast density, and, thus, should be further studied as a bioactive interface for orthopedic applications.
\end{abstract}

Keywords: nanostructure, adhesion, proliferation, preosteoblast, orthopedics

\section{Introduction}

In recent years, it has been recognized that biomaterial surface nanostructures greatly influence cellular behavior. ${ }^{1,2}$ Nanofeatured surfaces have been investigated as a potential tool for selectively increasing desirable cell functions while simultaneously decreasing competitive cell functions. ${ }^{3-5}$ Therefore, these intriguing results may open up the possibility for controlling cell behaviors, not by using pharmaceutical agents, but by simply adapting nanometer surface properties to the desired cell behavior. For example, many studies have indicated that nanotubular and nanotextured titania (created through various anodization conditions) could modulate the functions of many types of cells and might be used as an excellent bioactive interface for implantable devices. ${ }^{6-8}$ Specifically, it has been reported that fine-tuning the dimensions of such titania nanofeatures in the 10-200 $\mathrm{nm}$ range can enhance functions of osteoblasts, chondrocytes, and endothelial cells. ${ }^{9,10}$ Anodization of titanium to form titania nanotubular structures has also been shown to inhibit bacteria growth and macrophage (ie, inflammatory cell) functions; again, all without the use of pharmaceutical agents, which may have harmful side effects. ${ }^{9}$

Similar to titania nanotube arrays, porous anodic alumina (PAA) is a self-organized material with nanopore arrays that has a relatively long-range order of nanoporous structures. ${ }^{11}$ In addition, the PAA porous structure can be uniquely altered by varying
Correspondence: Siyu Ni

Engineering and Biotechnology, Donghua University, 2999 North Renmin Road,

Songjiang District, Shanghai 201620,

People's Republic of China

Tel +862167792752

Fax +8621 67792647

Email synicn@dhu.edu.cn 
anodization processing parameters and resulting porous shapes can be tailored with specific pore diameters. ${ }^{12,13}$ In particular, PAA has become increasingly important in biomedical applications over the past years because of its chemical stability as well as orthopedic biomimetic and biologicallyinspired properties. ${ }^{14-19}$ Recently, Wang et al and $\mathrm{Hu}$ et al studied NIH 3T3 (fibroblasts) and PC12 (pheochromocytoma) cellular behaviors on PAA with different pore sizes, but the nanopore arrays used in their study were in a disordered arrangement and pore size distribution was not even. ${ }^{20-22}$ Dalby et al have previously proved that nanoscale disorder on substrates also directly influenced cellular behaviors. ${ }^{23}$ Thus, the disorder of the porous arrangement may interfere with cell sensing of the different sized pores on PAA in their study. In another study, Chung et al studied the growth of epithelial normal cells (HMEC) on PAA surfaces with pore diameters from $30 \mathrm{~nm}$ to $80 \mathrm{~nm} .{ }^{24}$ To improve numerous biomedical applications, PAA interactions with different types of cells need to be studied extensively to acquire a full understanding of the cellular responses to such anodized surfaces. In addition, to the best of our knowledge, little (if any) studies have systematically examined the behaviors of preosteoblasts on such nanoporous surfaces of PAA (with pores in the $0-100 \mathrm{~nm}$ range) and elucidated a mechanism for their altered behavior.

Herein, we took advantage of the structural features of nanoporous anodic alumina and designed highly ordered nanoporous arrays with different pore sizes $(0-100 \mathrm{~nm})$. We studied the effects of these nanoporous structures on the adhesion and proliferation behaviors of preosteoblasts, which might provide a deeper understanding of how nanoporous alumina can be used in numerous orthopedic applications.

\section{Materials and methods}

\section{Porous anodic alumina preparation}

The alumina nanostructured surfaces were fabricated according to a previously published protocol. ${ }^{25}$ In brief, PAA with different diameters were fabricated from pure aluminum (Shtongren Co., Ltd, Shanghai, People's Republic of China) foils using a two-step anodization process. ${ }^{26}$ High-purity (99.999\%) aluminum sheets $(8.0 \mathrm{~cm} \times 1.5 \mathrm{~cm} \times 0.5 \mathrm{~mm})$ were annealed in a muffle furnace (KDF-S70; Tokyo Rikakikai Co., LTD, Tokyo, Japan) at $400^{\circ} \mathrm{C}$ for 3 hours to remove surface residual stresses, then the oil contaminant on the metal surface was removed in a mixture of ethanol, dichloromethane, and acetone ( $\mathrm{v} / \mathrm{v}=1: 2: 1)$ (Sinopharm Chemical Reagent Co., Ltd, Shanghai, People's Republic of China). Then, they were electrochemically polished in a solution of phosphoric and sulfuric acid ( $\mathrm{v} / \mathrm{v}=3: 2)$ (Sinopharm Chemical Reagent Co., Ltd) at $4.8 \mathrm{Amps}$ and $80^{\circ} \mathrm{C}$ until the sheets appeared smooth and shiny. Anodization was performed in a two-step process using 0.4 M oxalic acid (Sinopharm Chemical Reagent Co., Ltd) at 40 V. During anodization, the electrolyte was vigorously stirred in order to achieve a required temperature and uniform concentration of the electrolyte. A lead sheet was used as a cathode. The anodization temperature was kept constant at $2^{\circ} \mathrm{C}$ throughout the process by cooling the solution with an ice bath. At the end of the first anodization step, the alumina layer that formed was etched in a $4 \mathrm{wt} \%$ chromic acid and $8 \%(\mathrm{v} / \mathrm{v})$ phosphoric acid (Sinopharm Chemical Reagent Co., Ltd) mixture to form nucleation sites for later uniform pore formation. The second anodization step was performed under the same conditions as was used in the first electrolysis. After the second anodization step, the samples were immersed in a $5 \mathrm{wt} \%$ phosphoric acid solution at $37^{\circ} \mathrm{C}$ for widening the pores, and the etching time was regulated to obtain pores of different sizes. The pore widening time was controlled for 0,15 , and 40 minutes. Finally, the PAA samples were thoroughly rinsed with deionized water. For the cell experiments, all samples were cut into identical size pieces $(5 \mathrm{~mm} \times 5 \mathrm{~mm})$ and were sterilized using $70 \%$ ethanol and ultraviolet light for 30 minutes and 4 hours, respectively. Then, they were air dried overnight. Smoothly electrochemically polished aluminum with a native alumina $\left(\mathrm{Al}_{2} \mathrm{O}_{3}\right)$ oxide layer having a chemical composition analogous to that of a PAA surface was used as a control surface.

\section{Surface characterization}

The surface elemental composition and pore structure of the specimens were characterized using X-ray photoelectron spectroscopy (XPS) (Escalab250; Thermo Fisher Scientific, Waltham, MA, USA) and a field emission scanning electron microscope (FESEM) (JSE-5600LV; JEOL, Tokyo, Japan). The average roughness ( $\mathrm{Ra}$ ) was measured using a surface stylus profilometer (Wyko NT9100; Veeco Instruments, Inc., Plainview, NY, USA). Contact angles were determined with a video-based optical contact measuring system (OCA40Micro; Dataphysics, Filderstadt, German). The contact angles were measured using deionized water at room temperature. At least five measurements were carried out for every sample. In order to characterize the PAA structure, the calculation of some structural parameters (such as pore size, pore center-tocenter distance, wall thickness, porosity, and pore density) was carried out by using Adobe Photoshop CS2 software (Adobe Systems Incorporated, San Jose, CA, USA). Pore 
diameter, inter-pore distance (a measure of the pore-centerto-pore-center distance), and wall thickness were measured directly from the FESEM images. The porosity was calculated based on pore area of the unit cell divided by unit cell area. Pore density was evaluated based on field emission scanning electron microscope images by counting the number of pores per field for a given area.

\section{Cell culture}

A preosteoblast cell line derived from murine calvaria (MC3T3-E1 Subclone 4) was purchased from ATCC (Manassas, VA, USA). Preosteoblasts were cultured in alpha minimum essential medium (Thermo Fisher Scientific) supplemented with $10 \%$ heat-inactivated fetal calf serum (Thermo Fisher Scientific), L-glutamine (Thermo Fisher Scientific), $100 \mathrm{UI} / \mathrm{mL}$ penicillin, and $100 \mu \mathrm{g} / \mathrm{mL}$ streptomycin (Thermo Fisher Scientific), and were incubated in a $75 \mathrm{~cm}^{2}$ flask (Corning Incorporated, Corning, NY, USA) at $37^{\circ} \mathrm{C}$ under a humidified atmosphere consisting of $5 \% \mathrm{CO}_{2}$. Cell culture media was refreshed every 2 days. When cell experiments were performed, cells were harvested from tissue culture flasks using a trypsin-EDTA treatment, collected by centrifugation, and resuspended in alpha minimum essential medium. The cells were counted using a hemacytometer and the cell concentration calculated. Generation-three to -seven cells were used for all cell experiments.

\section{Cell morphology}

The cell morphology on the different samples after 4 and 24 hours was observed using FESEM (JSE-5600LV; JEOL). Samples were washed with a phosphate-buffered saline (PBS) solution twice and fixed in $2.5 \%$ glutaraldehyde (Sinopharm Chemical Reagent Co., Ltd) in a $0.1 \mathrm{M}$ sodium phosphate-buffered solution for 30 minutes. The fixed cells were washed three times with a PBS solution and then dehydrated in ascending concentrations of ethanol (30\%, 50\%, 70\%, 90\%, 95\%, and $100 \%$ [v/v]) for 10 minutes each. The specimens were prepared for drying by immersion first in a 50\% alcohol-hexamethyldisilazane (Sinopharm Chemical Reagent Co., Ltd) solution (v/v) for 10 minutes and then in pure hexamethyldisilazane for 5 minutes. They were air dried in a desiccator overnight. ${ }^{27}$ The dried specimens were glued onto copper specimen stubs and sputter-coated with gold before observation.

\section{Cell attachment and proliferation assay}

For cell adhesion experiments, cells were seeded onto the substrates at a density of $1 \times 10^{4}$ cells/sample. Cells were allowed to adhere for 1 hour before the wells were gently flooded with medium (1 mL/well). Cell attachment was determined after incubating for 2 and 4 hours. Cell proliferation was evaluated after seeding cells at a density of $2 \times 10^{3}$ cells/sample followed by incubation for 3 and 7 days. Medium was replaced every second day. Changes in the number of viable cells on the substrates were quantitatively assessed by using the WST-8 based Colorimetric Assay (Cell Counting Kit-8 [CCK-8]; Dojindo Laboratories, Kumamoto, Japan) test. ${ }^{24}$ WST-8 (2-(2-methoxy-4-nitrophenyl)-3(4-nitrophenyl)-5-(2,4-disulfophenyl)-2H-tetrazolium) is reduced by dehydrogenase in cells to give an orange colored product such as WST-8 formazan, which is soluble in the tissue culture medium. The amount of the WST- 8 formazan dye generated by dehydrogenase in cells is directly proportional to the number of living cells. In brief, at the prescribed time point, the samples were rinsed with PBS and transferred to new 48-well plates. Three hundred microliters of the cell culture medium and $30 \mu \mathrm{L}$ of the CCK-8 solution were added to each sample and incubated at $37^{\circ} \mathrm{C}$ for 2 hours. The absorbance at $450 \mathrm{~nm}$ with a reference wavelength at $650 \mathrm{~nm}$ was measured on a multimode microplate reader (EPOCH; BioTek Instruments, Inc., Winooski, VT, USA). The viable cell number was determined from a standard curve of absorbance versus known concentrations of MC3T3-E1 cells in solution run in parallel with the CCK-8 assay. Five specimens of each material were tested for each incubation time and each test was performed in triplicate.

\section{Protein adsorption}

The adsorption of bovine serum albumin (Sangon, Shanghai, People's Republic of China) on PAA samples was measured in this study. First, $200 \mu \mathrm{L}$ of the protein solution $(500 \mu \mathrm{g} / \mathrm{mL})$ was added to the different sized PAA, which were placed in a 48 -well plate. The adsorption study was conducted in a $37^{\circ} \mathrm{C}$ incubator for $0.5,2$, 4, and 6 hours, separately. Then, the PAA samples were transferred to a new well plate and rinsed carefully with PBS buffer to remove the nonadherent proteins. The bicinchoninic acid method was used to measure the adsorbed proteins on the PAA. Briefly, $200 \mu \mathrm{L}$ of a sodium dodecylsulfonate solution ( $1 \%$ $\mathrm{v} / \mathrm{v}$ ) was added to the well plate to desorb the proteins from the PAA surfaces. After shaking the well plate for $30 \mathrm{~min}$ utes at room temperature, the desorption fraction was then determined in a 96-well plate using the micro bicinchoninic protein assay reagent kit (Sangon) at $570 \mathrm{~nm}$ with an enzyme labeling instrument (MK 3; Thermo Fisher Scientific). 
Five specimens of each material were tested at each incubation time and each test was performed in triplicate.

\section{Statistical analyses}

Statistical analyses were completed using one-way analysis of variance followed by a post hoc test. All results were expressed as mean \pm standard deviation from the quintuple samples in each experiment. Differences were considered statistically significant at $P<0.05$.

\section{Results}

\section{Characterization of the prepared samples}

Figure $1 \mathrm{~A}-\mathrm{C}$ shows the FESEM micrographs of the $25 \mathrm{~nm}$, $50 \mathrm{~nm}$, and $75 \mathrm{~nm}$ nanoporous PAA samples, respectively. In order to present the data clearly, PAA with tunable pore sizes $(25 \mathrm{~nm}, 50 \mathrm{~nm}$, and $75 \mathrm{~nm}$ ) were denoted as PAA25, PAA50, and PAA75, respectively, according to the pore diameters on the PAA surfaces. The images reflect changes in the nanostructure because of differences in the pore size. As can be seen, all the anodized substrates showed a highly ordered and uniform nanoporous honeycomb morphology with long-range order. Flat aluminum appeared relatively smooth as expected (Figure 1D).

The surface composition of the different substrates was determined by XPS as shown in Figure 2. The main elements in the PAA and flat aluminum were carbon, oxygen, and aluminum, with traces of phosphorus. The XPS analysis also confirmed the presence of $\mathrm{Al}_{2} \mathrm{O}_{3}$ on the $\mathrm{Al}$ substrates. The $\mathrm{Ra}$ values of the different surfaces are shown in Table 1. With the increase of the pore size on the PAA surfaces, the average surface roughness shifted from $107.7 \mathrm{~nm}$ to $166.7 \mathrm{~nm}$. The Ra value for the flat aluminum was around $78.4 \mathrm{~nm}$. As expected, the nanopore surfaces were rougher than the flat aluminum.

The wettability of the different surfaces was determined by measuring contact angles. Flat aluminum had the strongest hydrophilic properties with a contact angle of $42.4^{\circ} \pm 2.4^{\circ}$. With the increase of pore size on the PAA surfaces (from $25 \mathrm{~nm}$ to $75 \mathrm{~nm}$ ), the water contact angles were $72.8^{\circ} \pm 2.8^{\circ}, 65.1 .9^{\circ} \pm 3.6^{\circ}$, and $86.5^{\circ} \pm 3.9^{\circ}$, respectively. Physical details of the PAA nanopores are portrayed in Table 2. The table summarizes the values of porosity density, inter-pore distance, wall thickness, and porosity variations with changes in pore diameters. The porosity of the PAA samples was influenced by pore size, which displayed a steady increase from $8.2 \%$ to $45.2 \%$ with an increase of pore size from $25 \mathrm{~nm}$ to $75 \mathrm{~nm}$; the wall thickness also decreased from $70 \mathrm{~nm}$ to $25 \mathrm{~nm}$ when the pore size varied from $25 \mathrm{~nm}$ to $75 \mathrm{~nm}$. However, the porosity density and the inter-pore distance were both homogeneous for all samples, reaching up to about $10.0 \times 10^{9} / \mathrm{cm}^{2}$ and $100 \mathrm{~nm}$, respectively.

\section{Cell morphology}

To investigate the influence of the different nanopore structures on cellular behavior, cell adhesion and shortterm cell growth for MC3T3-E1 cells were measured. The
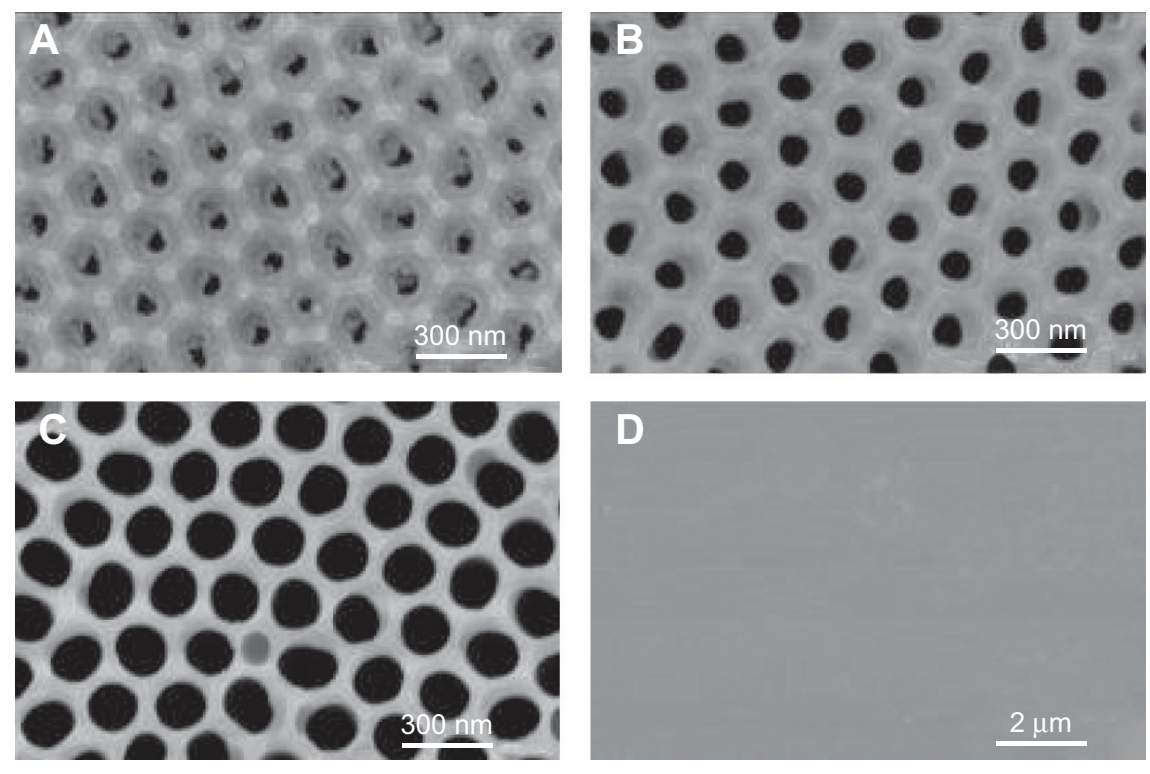

Figure I FESEM micrographs of flat aluminum and nanoporous anodic alumina membranes with three different pore diameters.

Notes: The images show highly ordered nanoporous structures with three different pore sizes: (A) nanoporous anodic alumina $25 \mathrm{~nm}$; (B) nanoporous anodic alumina $50 \mathrm{~nm}$; and (C) nanoporous anodic alumina $75 \mathrm{~nm}$. (D) Flat aluminum.

Abbreviation: FESEM, field emission scanning electron microscope. 
Table I Roughness and contact angle characterization of the aluminum substrates of interest

\begin{tabular}{lll}
\hline Sample & Roughness Ra $(\mathbf{n m})$ & Contact angle (degrees) \\
\hline Flat aluminum & $78.4 \pm 4.0$ & $42.4 \pm 2.4$ \\
PAA25 & $107.7 \pm 5.1$ & $72.8 \pm 2.8$ \\
PAA50 & $109.3 \pm 5.7$ & $65.1 \pm 3.6$ \\
PAA75 & $166.7 \pm 2.3$ & $86.5 \pm 3.9$ \\
\hline
\end{tabular}

Abbreviations: PAA25, porous anodic alumina with $25 \mathrm{~nm}$ pore size; PAA50, porous anodic alumina with $50 \mathrm{~nm}$ pore size; PAA75, porous anodic alumina with $75 \mathrm{~nm}$ pore size; Ra, average roughness.

adhesion of cells to the different substrates was determined at 2 and 4 hours. Representative images of adherent cells on PAA25, PAA50, PAA75, and flat aluminum are shown in Figure 3 (4 hours). After 4 hours, MC3T3-E1 cells exhibited a flattened and branched shape with differences in cell spreading on all the various substrates. Most cells had a branched shape, appearing flat with a smooth dorsal surface and, importantly, no round cells were found on the different substrates (Figure 3A-D). On high magnification scanning electron microscope micrographs, cell adhesion and morphology was characterized in more detail. It was observed that the cells had many filopodia anchored on/in many different pores simultaneously, resulting in an intensive cell-substrate interaction (Figure 3E-H).

After 24 hours of incubation, the spread cells maintained physical contact with each other, and the cells cultured on the surface of all the substrates appeared flat and progressed to form a monolayer. Furthermore, the MC3T3-E1 cells increased alignment on all of the samples (Figure 4A-D).

\section{Cell attachment and proliferation}

The relative number of cells adherent to the different substrates was assessed using a CCK-8 assay (Figure 5). For the MC3T3-E1 cells, the cell numbers increased with time on all the substrates, but adhesion was more rapid on the flat aluminum than on the PAA samples. More importantly, there was a higher number of cells on PAA75 than that on the PAA25 surfaces $(P<0.05)$. However, there was no significant difference in cell numbers between the PAA25 and PAA50 surfaces. After 4 hours of incubation, a similar trend was observed to that of cells cultured after 2 hours. MC3T3-E1 cell proliferation on PAA75 was greater as compared to the control substrates after 3 days of culture (Figure 6). In addition, the proliferation rates of cells on the $25 \mathrm{~nm}$ and $50 \mathrm{~nm}$ porous sized PAA were comparable to that of the controls. But after 7 days of growth, PAA50 and PAA75 clearly enhanced cell proliferation compared to controls $(P<0.05)$.

\section{Protein adsorption}

Bovine serum albumin adsorption on the different sized PAA after $0.5-6$ hours is presented in Figure 7. Results showed that the amounts of bovine serum albumin adsorbed on all specimens continued to increase with increasing adsorption time and all samples reached adsorption saturation after 6 hours. Results indicated that PAA75 had the strongest protein adsorption compared to other samples after all time periods, reaching up to $29.7 \mu \mathrm{g} / \mathrm{cm}^{2}$ after 6 hours. In contrast, flat aluminum showed significantly lower protein adsorption

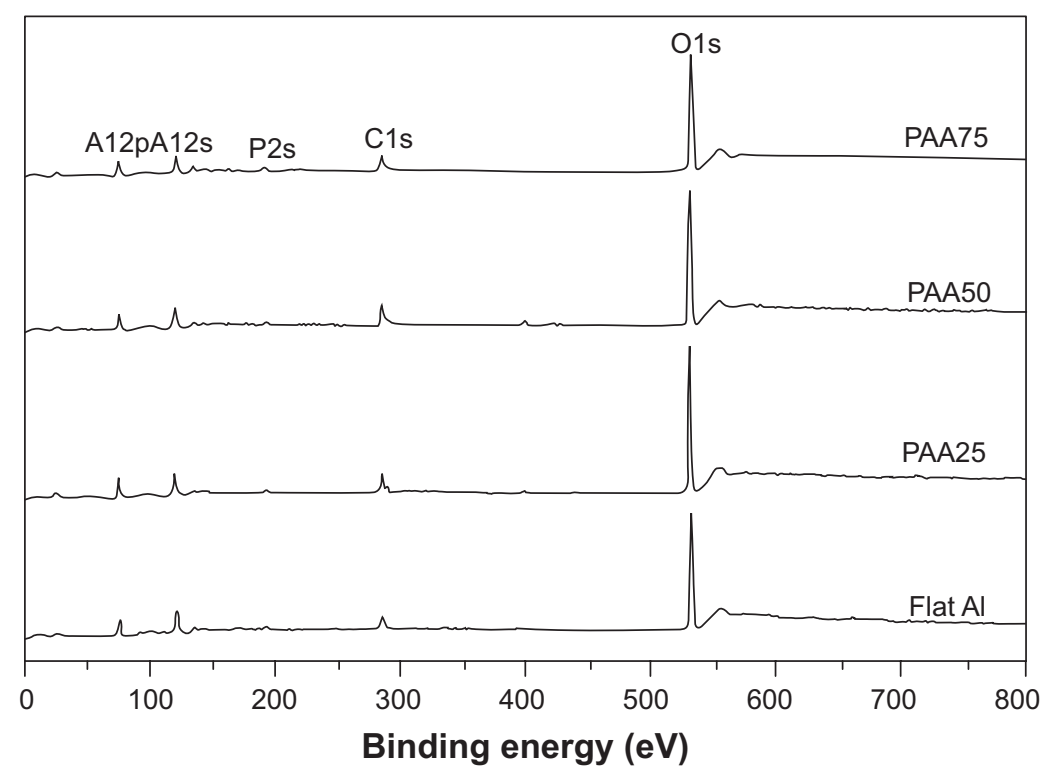

Figure 2 XPS survey spectra showing the chemical composition of the surfaces: (PAA25, PAA50, PAA75, and flat aluminum).

Abbreviations: Flat Al, flat aluminum; PAA25, porous anodic alumina with $25 \mathrm{~nm}$ pore size; PAA50, porous anodic alumina with $50 \mathrm{~nm}$ pore size; PAA75, porous anodic alumina with $75 \mathrm{~nm}$ pore size; XPS, X-ray photoelectron spectroscopy. 
Table 2 Porosity characterization of the aluminum substrates of interest

\begin{tabular}{lllll}
\hline Pore size $(\mathbf{n m})$ & $\begin{array}{l}\text { Porosity density } \\
\left(\text { pores } / \mathbf{c m}^{2}\right)\end{array}$ & $\begin{array}{l}\text { Inter-pore } \\
\text { distance }(\mathbf{n m})\end{array}$ & $\begin{array}{l}\text { Wall thickness } \\
(\mathbf{n m})\end{array}$ & Porosity $(\%)$ \\
\hline PAA25 (25) & $9.8 \times 10^{9}$ & 100 & 70 & $8.2 \%$ \\
PAA50 (50) & $10.4 \times 10^{9}$ & 100 & 50 & $19.1 \%$ \\
PAA75 (75) & $10.4 \times 10^{9}$ & 100 & 25 & $45.2 \%$ \\
\hline
\end{tabular}

Abbreviations: PAA25, porous anodic alumina with $25 \mathrm{~nm}$ pore size; PAA50, porous anodic alumina with $50 \mathrm{~nm}$ pore size; PAA75, porous anodic alumina with $75 \mathrm{~nm}$ pore size.
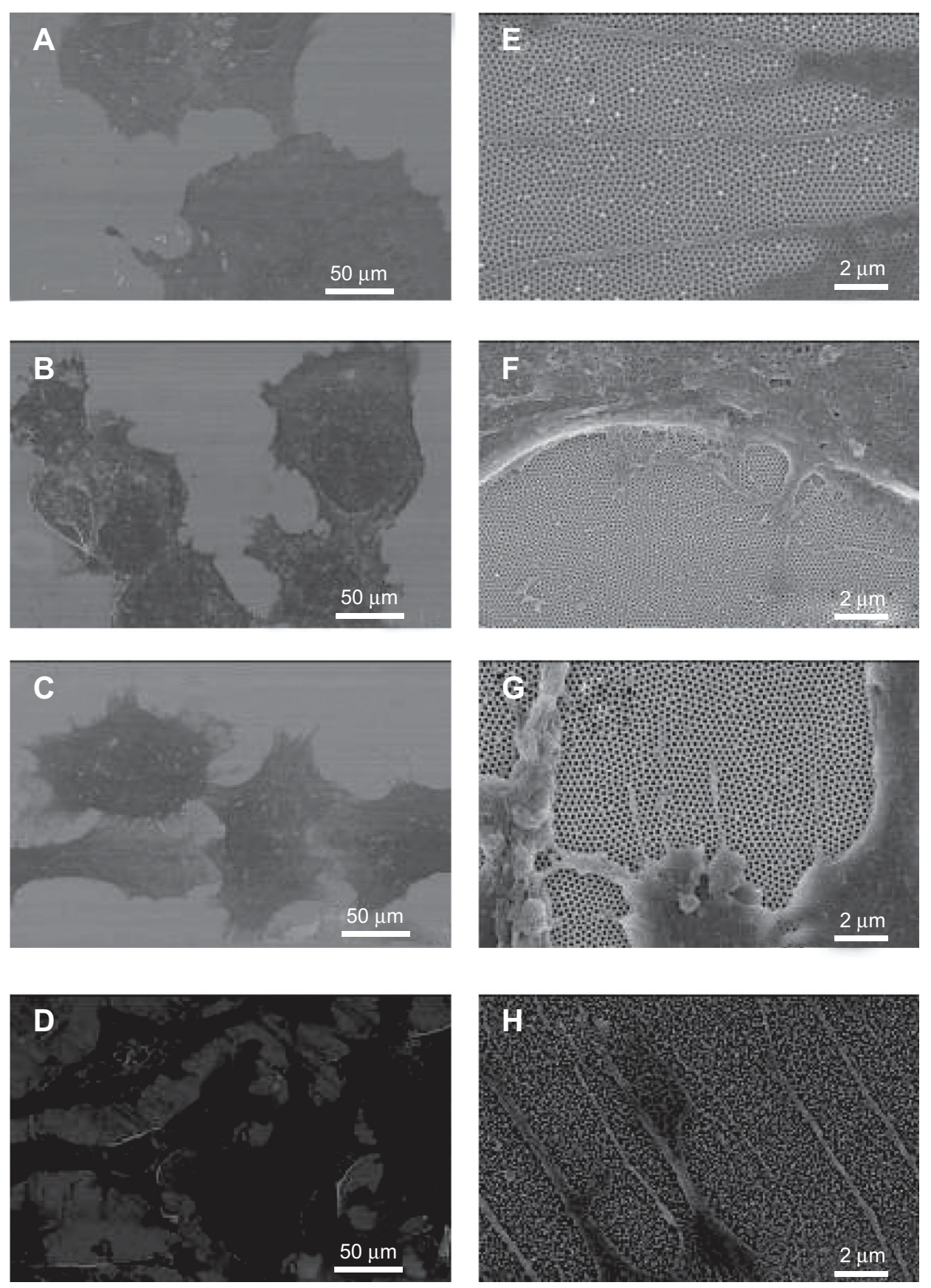

Figure 3 FESEM micrographs after 4 hours of incubation.

Notes: FESEM micrographs of: (A and E) PAA25; (B and F) PAA50; (C and G) PAA75; and (D and $\mathbf{H})$ flat aluminum seeded with MC3T3-EI preosteoblast cells after 4 hours of incubation. $\mathbf{E}, \mathbf{F}, \mathbf{G}$ and $\mathbf{H}$ are high magnification images. The images depict the main characteristics of interest on each substrate.

Abbreviations: PAA25, porous anodic alumina with $25 \mathrm{~nm}$ pore size; PAA50, porous anodic alumina with $50 \mathrm{~nm}$ pore size; PAA75, porous anodic alumina with 75 nm pore size; FESEM, field emission scanning electron microscope. 

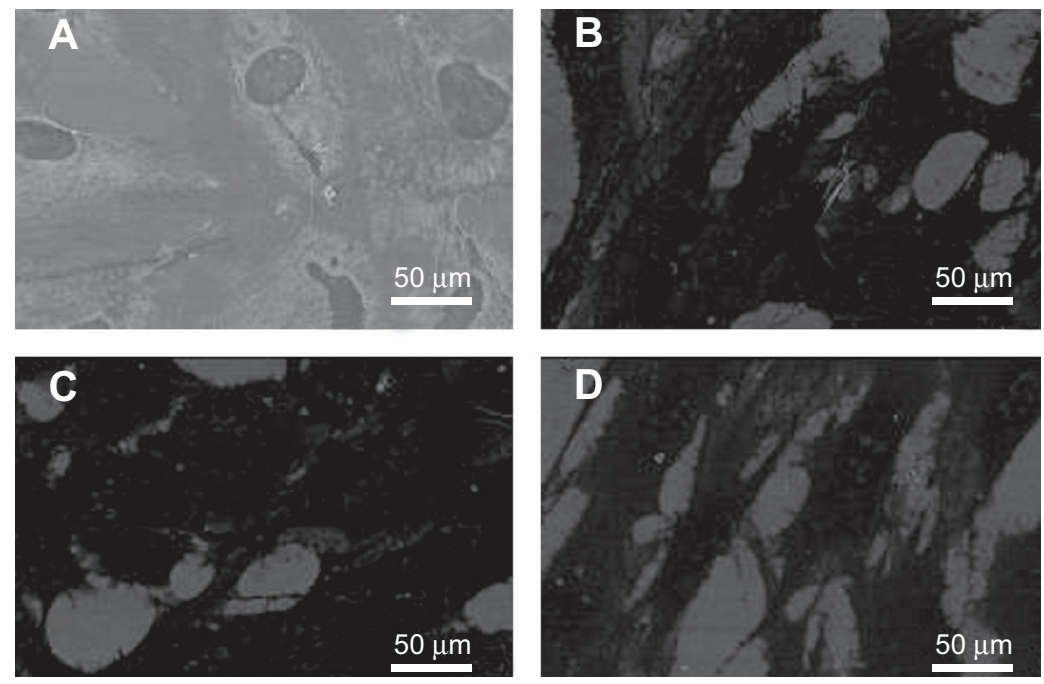

Figure 4 FESEM micrographs after 24 hours of incubation.

Notes: FESEM micrographs of (A) PAA25, (B) PAA50, (C) PAA75, and (D) flat aluminum seeded with MC3T3-EI preosteoblast cells after 24 hours of incubation.

Abbreviations: PAA25, porous anodic alumina with $25 \mathrm{~nm}$ pore size; PAA50, porous anodic alumina with 50 nm pore size; PAA75, porous anodic alumina with $75 \mathrm{~nm}$ pore size; FESEM, field emission scanning electron microscope.

amounts compared with PAA50 and PAA75 after 6 hours, and the overall amount of protein adsorption on flat aluminum only reached $15.9 \mu \mathrm{g} / \mathrm{cm}^{2}$.

\section{Discussion}

It is now increasingly recognized that the physical as well as the chemical properties of materials can regulate biological responses. ${ }^{2}$ Physical guidance is considered to be an effective method to elicit specific cellular responses and direct new tissue formation for the development of improved

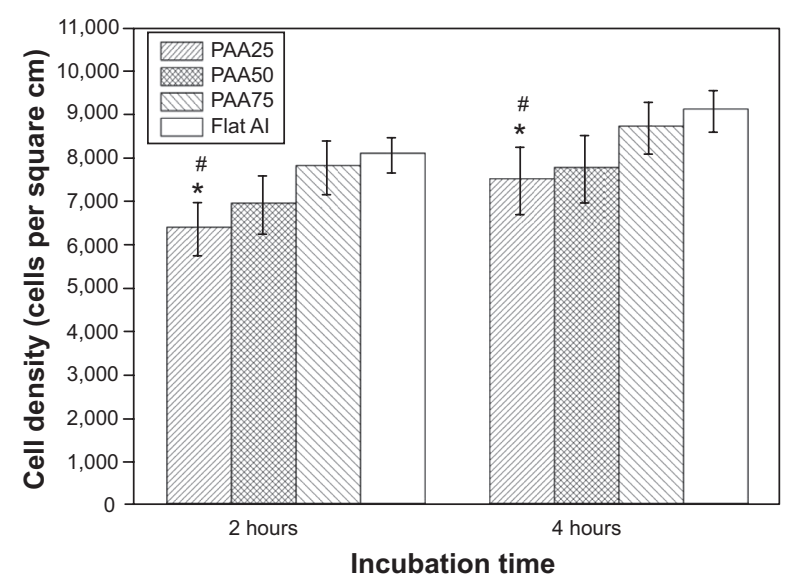

Figure 5 Evaluation of MC3T3-EI cell adhesion on the PAA membranes of different pore sizes and flat aluminum.

Notes: Data are represented as mean \pm standard deviation, $n=5$. Both substrates were seeded with $1 \times 10^{4}$ cells. $* P<0.05$ compared to the flat aluminum; ${ }^{*}$ denotes a significant difference between the PAA75 and PAA25.

Abbreviations: Flat Al, flat aluminum; PAA, porous anodic alumina; PAA25, PAA with $25 \mathrm{~nm}$ pore size; PAA50, PAA with $50 \mathrm{~nm}$ pore size; PAA75, PAA with $75 \mathrm{~nm}$ pore size. biomaterials. ${ }^{28}$ In this study, the behavior of MC3T3-E1 cells on different sized PAA was investigated and compared. Ordered nanoporous surfaces with different pore sizes demonstrated an ability to influence MC3T3-E1 cell activity. Explaining this behavior requires an understanding of the many surface parameters characterized here among the various samples that can influence cellular responses, including surface chemical composition, surface energy, and topography.

Importantly, the detailed XPS analysis indicated that the different PAA nanoporous surfaces and polished aluminum

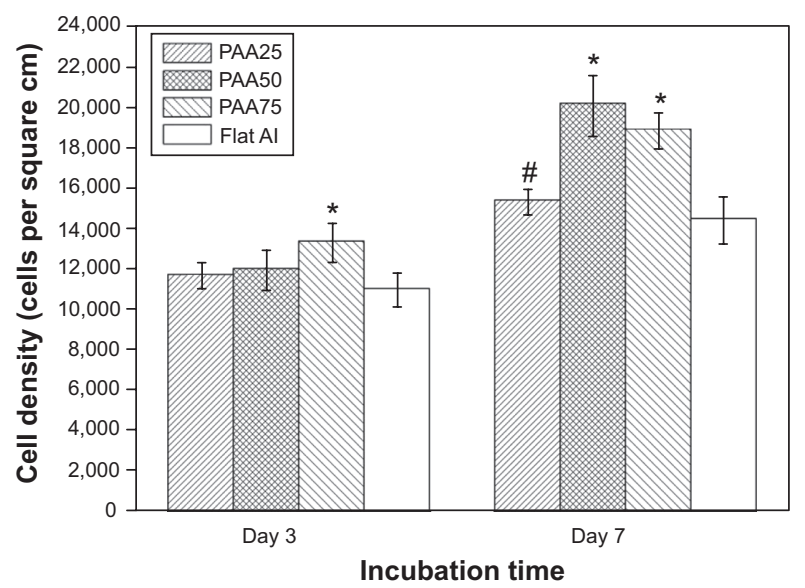

Figure 6 Evaluation of MC3T3-EI preosteoblast cell proliferation on the PAA membranes of different pore sizes and flat aluminum.

Notes: Data are represented as mean \pm standard deviation, $n=5$. Both substrates were seeded with $2 \times 10^{3}$ cells. $* P<0.05$ compared to the flat aluminum; \#denotes a significant difference between the PAA25, PAA50, and PAA75.

Abbreviations: Flat Al, flat aluminum; PAA, porous anodic alumina; PAA25, PAA with $25 \mathrm{~nm}$ pore size; PAA50, PAA with $50 \mathrm{~nm}$ pore size; PAA75, PAA with $75 \mathrm{~nm}$ pore size. 


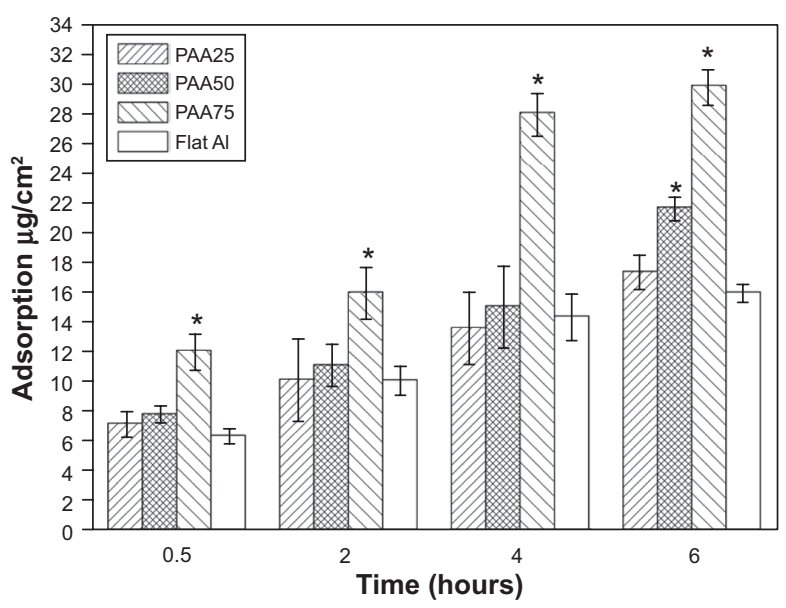

Figure 7 Dynamic bovine serum albumin adsorption on the different sized PAA surfaces.

Notes: Data are represented as mean \pm standard deviation, $n=5$. $* p<0.05$ compared to the flat aluminum.

Abbreviations: Flat Al, flat aluminum; PAA, porous anodic alumina; PAA25, PAA with $25 \mathrm{~nm}$ pore size; PAA50, PAA with $50 \mathrm{~nm}$ pore size; PAA 75, PAA with 75 nm pore size.

had similar surface chemical composition. Moreover, the as-prepared PAA materials were found to be amorphous, similar to the surface of flat aluminum (data not shown here). Thus, this work was able to focus on elucidating changes in cellular behavior based on nanostructured surface features alone.

It has been reported that cellular adhesion is sensitive to surface roughness. In most cases, high surface roughness of a material leads to enhanced cell adhesion. ${ }^{29}$ In the present study, the PAA25, PAA50, and PAA75 showed a mean roughness of $107.7 \mathrm{~nm}, 109.3 \mathrm{~nm}$, and $166.7 \mathrm{~nm}$, respectively. Such values are in the range $(0.11-0.28 \mu \mathrm{m})$ reported to influence osteoblast-like cell activity. ${ }^{30}$ Our results suggest again that MC3T3-E1 cells grew more on nano-rough PAA than on nano-smooth PAA.

Previous studies have confirmed the positive influence of hydrophilicity towards early osteoblast attachment. ${ }^{31,32}$ Hydrophilic surfaces have been found favorable for the rapid attachment and spreading of osteoblasts. The improved wettability of surfaces indicates higher surface energies. ${ }^{33}$ Such changes in surface wettability influence the type, conformation, and bioactivity of proteins to alter the establishment of focal contacts from cells. ${ }^{34}$ Interestingly, in this study, flat aluminum had the lowest contact angles among the surfaces studied, indicating that it had higher surface energy than the other samples, possibly rendering the surface more favorable for MC3T3-E1 cell attachment. However, surface nanometer topography is another important property that could expose numerous amino acids in adsorbed proteins to promote focal adhesion contacts. ${ }^{29}$
To demonstrate how changes in surface nanometer roughness alone (not accompanied by changes in surface chemistry) can influence protein adsorption, the adsorption of bovine serum albumin to the different surfaces was explored here. Recent studies have indicated that the macromolecular interactions of bovine serum albumin with preosteoblasts leads to higher expression levels of fibronectin, vinculin, and actin stress fibers, which could be beneficial in prompting MC3T3-E1 cellular functions. ${ }^{35,36}$ PAA75 significantly enhanced the adsorption of bovine serum albumin to its surfaces as compared to PAA25 and PAA50. Therefore, although requiring more investigation, it is reasonable to hypothesize that a synergistic effect of these factors (surface nanometer roughness changes leading to changes in surface energy and, consequently, changes in initial protein adsorption) leads to improved MC3T3-E1 cell growth on PAA75 compared to on flat aluminum.

Of course, cell attachment is a complicated process that involves numerous proteins. The conformation and bioactivity of the protein is also crucial. All of the changes in protein interactions need to be determined to fully understand the greater cell growth on such PAA surfaces. This is especially intriguing as our results suggest that the aluminum nanostructure did not enhance cell adhesion during the initial stage of MC3T3-E1 cell culture. Similar results have been obtained by others. For example, Chung et al recently studied the adhesion of epithelial cells on various nanoporous alumina surfaces and found that the adhesion rate of cells on nanoporous surfaces ( 0 [flat aluminum], 30, 40, and $45 \mathrm{~nm}$ ) did not vary, and even the number of cells that adhered to the $50 \mathrm{~nm}$ and $80 \mathrm{~nm}$ sized nanoporous surfaces was slightly lower than controls. They explained that this phenomenon was most likely due to a lack of surface area to which the cells could adhere when the pore size increased. In other words, more open porosity leads to less surface area for cell attachment. ${ }^{24}$ Therefore, the flat aluminum in the present work might provide more surface area for initial cell attachment as compared to the nanoporous surface. Although it is difficult to evaluate whether surface area or hydrophilicity is more influential towards the initial MC3T3-E1 cell attachment on the present materials, the results from this study suggest that both parameters may be responsible for promoting the attachment of MC3T3-E1 cells on flat aluminum, which needs to be further explored.

Nonetheless, cell proliferation was affected by surface topography and roughness. Recent findings indicated that surface nanomorphology was even more important for the long-term proliferation capacity of cells. ${ }^{37,38}$ For example, 
Chung et al found that the proliferation of epithelial cells was influenced by the small pore sizes of the nanoporous surface because the small (in their case, $30 \mathrm{~nm}$ ) nanostructure could control the interaction between extracellular matrix molecules and the surface. ${ }^{24}$ Wang et al also showed that the optimal pore size of aluminum oxide membranes for cell growth was $80 \mathrm{~nm}$ for PC12 cells and $50 \mathrm{~nm}$ for NIH $3 \mathrm{~T} 3$ cells. ${ }^{20}$ However, in another study, they also found that the topographical changes at the nanoscale on aluminum oxide membrane's surfaces showed no significant effects on the viability and proliferation of rat mesenchymal stem cells. ${ }^{21}$ The differences in these observations might be explained by the different surface topographies employed in PAA and the different cell types investigated, which does not allow for proper comparisons between them. Most importantly, in our study, higher levels of cell proliferation were observed on the PAA50 and PAA75 than on the PAA25 and flat aluminum after 7 days of culture. The porous surfaces with larger pore sizes $(50 \mathrm{~nm}$ and $75 \mathrm{~nm}$ ) improved roughness and bovine serum albumin adsorption, which might be major factors contributing to improved MC3T3-E1 cell proliferation. Further studies are now aimed towards fabricating a wide range of pore sizes of PAA and investigating the genetic mechanisms of cell-PAA interactions with a particular focus on preosteoblast differentiation, which would be helpful for a deeper understanding of the influence of this porous structure on a number of medical applications.

\section{Conclusion}

In this study, highly ordered PAA of defined pore sizes ranging from $25 \mathrm{~nm}$ to $75 \mathrm{~nm}$ were prepared by a two-step anodization technique. The attachment and proliferation of MC3T3-E1 on different sized PAA surfaces were assessed and compared. It was found that the nanoporous changes on PAA surfaces could modulate surface roughness, wettability, and bovine serum albumin adsorption at early stages of cell growth (up to 7 days). Of particular interest, nanoporous surfaces did not enhance MC3T3-E1 cell attachment whereas cell proliferation dramatically increased when the pore size was $50 \mathrm{~nm}$ and $75 \mathrm{~nm}$. Porous surfaces with relatively larger pore sizes (50 nm and $75 \mathrm{~nm}$ ) improved roughness and bovine serum albumin adsorption, which might be responsible for improved MC3T3-E1 cell growth. Consequently, these results suggested that the MC3T3-E1 cell responses may be controlled and optimized by varying the pore size of PAA, and the nanoporous surfaces can be designed to support osteoblast growth, which is important for improving orthopedic materials.

\section{Acknowledgments}

This work was supported by the Natural Science Foundation of China (Grant No. 50902020), the Fundamental Research Funds for the Central Universities (Grant No. 2014D1 10507), and the Opening Foundation of Zhejiang Provincial Top Key Discipline (Grant No. 20110925). The authors would like to acknowledge the Tissue Engineering Research Center of Shanghai Ninth People's Hospital for assistance with cell experiments.

\section{Disclosure}

The authors report no conflicts of interest in this work.

\section{References}

1. Martínez E, Engel E, Planell JA, Samitier J. Effects of artificial micro- and nano-structured surfaces on cell behavior. Ann Anat. 2009; 191(1):126-135.

2. Mitragotri S, Lahann J. Physical approaches to biomaterial design. Nat Mater. 2009;8(1):15-23.

3. Lee J, Kang BS, Hicks B, et al. The control of cell adhesion and viability by zinc oxide nanorods. Biomaterials. 2008;29(27):3743-3749.

4. Richert L, Vetrone F, Yi JH, et al. Surface nanopatterning to control cell growth. Adv Mater. 2008;20(8):1488-1492.

5. Smith BS, Yoriya S, Johnson T, Popat KC. Dermal fibroblast and epidermal keratinocyte functionality on titania nanotube arrays. Acta Biomater. 2011;7(6):2686-2696.

6. Park J, Bauer S, von der Mark K, Schmuki P. Nanosize and vitality: $\mathrm{TiO}_{2}$ nanotube diameter directs cell fate. Nano Lett. 2007;7(6):1686-1691.

7. Durmus NG, Webster TJ. Nanostructured titanium: the ideal material for improving orthopedic implant efficacy? Nanomedicine. 2012; 7(6):791-793.

8. Brammer KS, Oh S, Cobb CJ, Bjursten LM, van de Heyde H, Jin S. Improved bone-forming functionality on diameter-controlled $\mathrm{TiO}_{2}$ nanotube surface. Acta Biomater. 2009;5(8):3215-3223.

9. Ercan B, Taylor E, Alpaslan E, Webster TJ. Diameter of titanium nanotubes influences anti-bacterial efficacy. Nanotechnology. 2011; 22(29):295102.

10. Khang D, Lu J, Yao C, Haberstroh KM, Webster TJ. The role of nanometer and sub-micron surface features on vascular and bone cell adhesion on titanium. Biomaterials. 2008;29(8):970-983.

11. Li AP, Müller F, Birner A, Nielsch K, Gösele U. Hexagonal pore arrays with a $50-420 \mathrm{~nm}$ interpore distance formed by self-organization in anodic alumina. J Appl Phys. 1998;84(11):6023-6026.

12. Chen W, Wu JS, Xia XH. Porous anodic alumina with continuously manipulated pore/cell size. ACS Nano. 2008;2(5):959-965.

13. Li YB, Zheng MJ, Ma L, Shen WZ. Fabrication of highly ordered nanoporous alumina films by stable high-field anodization. Nanotechnology. 2006;17(20):5101-5105.

14. Norman JJ, Desai TA. Methods for fabrication of nanoscale topography for tissue engineering scaffolds. Ann Biomed Eng. 2006;34(1): 89-101.

15. Briggs EP, Walpole AR, Wilshaw PR, Karlsson M, Pålsgård E. Formation of highly adherent nano-porous alumina on Ti-based substrates: a novel bone implant coating. J Mater Sci Mater Med. 2004; 15(9):1021-1029.

16. Popat KC, Leary Swan EE, Mukhatyar V, et al. Influence of nanoporous alumina membranes on long-term osteoblast response. Biomaterials. 2005;26(22):4516-4522.

17. Swan EE, Popat KC, Grimes CA, Desai TA. Fabrication and evaluation of nanoporous alumina membranes for osteoblast culture. $J$ Biomed Mater Res A. 2005;72(3):288-295. 
18. Karlsson M, Tang L. Surface morphology and adsorbed proteins affect phagocyte response to nano-porous alumina. J Mater Sci Mater Med. 2006;17(11):1101-1111.

19. Hoess A, Teuscher N, Thormann A, Aurich H, Heilmann A. Cultivation of hepatoma cell line HepG2 on nanoporous aluminum oxide membranes. Acta Biomater. 2007;3(1):43-50.

20. Wang HJ, Sun YY, Cao Y, et al. Is there an optimal topographical surface in nano-scale affecting protein adsorption and cell behaviors? Part II. J Nanopart Res. 2012;14(5):862-871.

21. Wang HJ, Cao Y, Sun YY, et al. Is there an optimal topographical surface in nano-scale affecting protein adsorption and cell behaviors? J Nanopart Res. 2011;13(9):4201-4210.

22. Hu J, Tian JH, Shi J, et al. Cell culture on AAO nanoporous substrated with and without geometry constrains. Microelectron Eng. 2011;88(8): 1714-1717.

23. Dalby MJ, Gadegaard N, Tare R, et al. The control of human mesenchymal cell differentiation using nanoscale symmetry and disorder. Nat Mater. 2007;6(12):997-1003.

24. Chung SH, Son SJ, Min J. The nanostructure effect on the adhesion and growth rates of epithelial cells with well-defined nanoporous alumina substrates. Nanotechnology. 2010;21(12):125104.

25. Sulka GD, Brzózka A, Zaraska L, Jaskula M. Through-hole membranes of nanoporous alumina formed by anodizing in oxalic acid and their applications in fabrication of nanowire arrays. Electrochim Acta. 2010;55(14):4368-4376.

26. Masuda H, Fukuda K. Ordered metal nanohole arrays made by a 2-step replication of honeycomb structure of anodic alumina. Science. 1995;268(5216):1466-1468.

27. Ni SY, Lin KL, Chang J, Chou L. $\beta-\mathrm{CaSiO}_{3} / \beta-\mathrm{Ca}_{3}\left(\mathrm{PO}_{4}\right)_{2}$ composite materials for hard tissue repair: In vitro studies. $J$ Biomed Mater Res A. 2008;85A(1):72-82.

28. Lee JW, Lee KS, Cho N, Ju BK, Lee KB, Lee SH. Topographical guidance of mouse neuronal cell $\mathrm{SiO}_{2}$ microtracks. Sensor Actuat B Chem. 2007;128(1):252-257.
29. Neupane MP, Park I1 S, Bae TS, Yi HK, Watari F, Lee MH. Biocompatibility of $\mathrm{TiO}_{2}$ nanotubes fabricated on Ti using different surfactant additives in electrolyte. Mater Chem Phys. 2012;134(1):536-541.

30. Lincks J, Boyan BD, Blanchard CR, et al. Response of MG63 osteoblast-like cells to titanium and titanium alloy is dependent on surface roughness and composition. Biomaterials. 1998;19(23):2219-2232.

31. Wei JH, Igarashi T, Okumori N, et al. Influence of surface wettability on competitive protein adsorption and initial attachment of osteoblasts. Biomed Mater. 2009;4(4):045002.

32. Thian ES, Ahmad Z, Huang J, et al. The role of surface wettability and surface charge of electrosprayed nanoapatites on the behaviour osteoblasts. Acta Biomater. 2010;6(3):750-755.

33. Carpenter J, Khang D, Webster TJ. Nanometer polymer surface features: the influence on surface energy, protein adsorption and endothelial cell adhesion. Nanotechnology. 2008;19(50):505103.

34. Lim JY, Donahue HJ. Cell sensing and response to micro- and nanostructured surfaces produced by chemical and topographic patterning. Tissue Eng. 2007;13(8):1879-1891.

35. Misra RDK, Girase B, Nune VKC, Xu W. Cellular interactions and modulated osteoblasts functions mediated by protein adsorption. $A d v$ Eng Mater. 2012;14(5):B247-B257.

36. Misra RD, Nune C, Pesacreta TC, Somani MC, Karjalainen LP. Interplay between grain structure and protein adsorption on functional response of osteoblasts: Ultrafine-grained versus coarse-grained substrates. J Biomed Mater Res A. 2013;101(1):1-12.

37. Bigerelle M, Anselme K. Statistical correlation between cell adhesion and proliferation on biocompatible metallic materials. J Biomed Mater Res A. 2005;72(1):36-46.

38. Anselme K, Bigerelle M, Noel B, et al. Qualitative and quantitative study of human osteoblast adhesion on materials with various surface roughnesses. J Biomed Mater Res. 2000;49(2):155-166.
International Journal of Nanomedicine

\section{Publish your work in this journal}

The International Journal of Nanomedicine is an international, peerreviewed journal focusing on the application of nanotechnology in diagnostics, therapeutics, and drug delivery systems throughout the biomedical field. This journal is indexed on PubMed Central, MedLine, CAS, SciSearch $®$, Current Contents ${ }^{\circledR} /$ Clinical Medicine,

\section{Dovepress}

Journal Citation Reports/Science Edition, EMBase, Scopus and the Elsevier Bibliographic databases. The manuscript management system is completely online and includes a very quick and fair peer-review system, which is all easy to use. Visit http://www.dovepress.com/ testimonials.php to read real quotes from published authors. 